\title{
Assessing a Transition to $100 \%$ Renewable Power Generation in a Non-interconnected Area: A Case Study for La R Eunion Island
}

Frederic Babonneau ( $\square$ fbabonneau@gmail.com )

Ordecsys https://orcid.org/0000-0002-3430-0314

Stéphane Biscaglia

ADEME

David Chotard

Artelia

Alain Haurie

Ordecsys

Nicolas Mairet

Enerdata

Thibaut Lefillatre

Artelia

\section{Research Article}

Keywords: Long-term energy planning, Dispatch model, Network stability, Variable renewable energy, Reserve requirements

Posted Date: June 24th, 2021

DOl: https://doi.org/10.21203/rs.3.rs-290690/v1

License: (c) (i) This work is licensed under a Creative Commons Attribution 4.0 International License. Read Full License 


\title{
Assessing a Transition to 100\% Renewable Power Generation in a Non-interconnected Area: A Case Study for La Réunion Island
}

\author{
Frédéric Babonneau ${ }^{\mathrm{a}, *}$, Stéphane Biscaglia ${ }^{\mathrm{b}}$, David Chotard ${ }^{\mathrm{c}}$, Alain Haurie ${ }^{\mathrm{d}}$, Nicolas \\ Mairet $^{\mathrm{e}}$, Thibaut Lefillatre ${ }^{\mathrm{c}}$ \\ ${ }^{a}$ Escuela de negocios, Universidad Adolfo Ibáñez, Santiago, Chile and ORDECSYS, Switzerland \\ ${ }^{b}$ ADEME, France \\ ${ }^{c}$ ARTELIA, France \\ ${ }^{d}$ ORDECSYS and University of Geneva, Switzerland \\ ${ }^{e}$ ENERDATA, France
}

\begin{abstract}
In this paper, we present a global and multi-timescale approach for assessing energy transition policies aiming at fully renewable generation in power systems of non-interconnected areas, typically islands or isolated regions. The approach links together three dynamic models:(i) a capacity expansion model, ETEM-SG, proposes an investment and production plan for typical days, at the horizon 2030; (ii) a simplified dispatch model is used to validate the production plan for a full year data of weather and demand variations and; (iii) a static \& dynamic power system analysis is used to assess the stability of the new power network for fast occurring events like, e.g., a sudden reduction of renewable production. The proposed three-stage approach generates a least-cost long-term investment planning that ensures a supply-demand balance at an hourly time-step and power network statibility at a few millisecond time scale. The presentaion is based on a case study fully described in a report [1] made with ADEME, the French Agency for ecological transition, for the French island La Réunion. It shows how a reliable $100 \%$ renewable power supply is reachable by 2030, in this area.
\end{abstract}

Keywords: Long-term energy planning, Dispatch model, Network stability, Variable renewable energy, Reserve requirements.

\footnotetext{
Electronic Supplementary Information (ESI) available.

*Corresponding author

Email address: frederic.babonneau@uai.cl (Frédéric Babonneau)
} 


\section{Introduction}

The ecological transition usually calls for the design of an energy policy that aims at an electrical power system based mainly, or even exclusively ${ }^{1}$, on renewable energy sources (RES) at the horizon 2030 or 2050. In France, for example, ADEME, the French Agency for ecological transition ${ }^{2}$, conducted in 2012 an energy prospective exercise for its metropolitan area, called Visions 2030-2050. In this study [7], important renewable energy production potentials were identified and deemed to be sufficient to cover the total energy demand in 2050 .

However, even though solar and wind energy sources are weather dependent yielding to intermittent production, these results were mainly based on annual energy volumes considerations. The question then arised whether a power system based mainly on these renewable energy sources could guarantee a quasi permanent supply-demand balance and the necessary stability of the networks. Another concern, particularly important for non-interconnected areas, typically islands or isolated regions, was to identify the need for reinforcement and extension of the transmission power network due to the new geographical distribution of production units (wind or solar farms, for example). Then, the stability of the new power system with an adapted transmission network should be assessed. So, ADEME wanted to adapt its approach to this reality, when addressing the transition to sustainable power systems in non-interconnected regions of the French territory ${ }^{3}$.

There exist many modeling approaches for planning a transition to a low carbon economy and thus a power system with renewable sources, see $[15,12,6,8,13]$ for a few of them. In general, these approaches do not consider power network reliability constraints in the energy model. This has been done in [9], where the authors, using thermodynamics considerations, introduce two reliability indicators in their TIMES model, as a way to deal with the very

\footnotetext{
${ }^{1}$ Typically $75 \%$ to $100 \%$ of the production mix.

${ }^{2}$ Agence de l'Environnement et de la Maîtrise de l'Énergie - Agency for ecological transition.

${ }^{3}$ This comprised islands of La Réunion, Mayotte, Corse, Guadeloupe, Martinique, and French Guyana.
} 
different timescales involved. They claim that these two indicators that measure magnetic and kinetic reserve enable a quantification of the reliability of a given production mix. This would permit a first assessment of a trade-off between increasing the share of intermittent production units and maintaining an expected level of reliability. In a different approach [3], power distribution constraints are introduced in the ETEM-SG model; they are associated with intermittent and volatile renewable energy sources connected at the transmission or distribution network. The model thus takes into account the ability of distributed energy resources (DER) to provide reserves, reactive power compensation, and shift their operation over time so as to reduce losses, congestion and wholesale energy costs. Thus, ADEME adopted an approach consisting of using ETEM-SG, complemented by an hourly dispatch study for a whole year of weather events and an analysis of network stability for fast time scale events.

The rest of the paper is organized as follows: In Section 2, we describe a global approach that uses three complementary tools for designing and validating reliable long-term energy policies with a $100 \%$ renewable objective. In Section 3, we introduce the case study of $L a$ Réunion, a French island in Indian ocean. In Section 4, we detail the extensive technoeconomic analysis. Finally, in Section 5, we conclude and envision further developments.

\section{A global multi-level approach}

A three-tiered approach, illustrated on Figure 1, is used to design a least-cost, robust and reliable transition towards a 100\% renewable target for non-interconnected areas. In a first tier, the techno-economic model ETEM-SG proposes an efficient transition to $100 \%$ renewables on the horizon 2030 period for the electricity sector ensuring of the region under consideration; in this design of the power system, specific constraints guarantee that an hourly supply-demand balance and secondary reserve requirements are satisfied on a set of typical days for different seasons. The second tier validates the proposed power system by simulating a complete hourly power dispatch for a target year, with a full history of weather and demand variations at the time scale of an hour. Adjustments on reserve requirement are then introduced in ETEM-SG when the dispatch is unfeasible. Finally, the third tier 
performs a static and dynamic analysis of the power grid to guaranty frequency and voltage stability for critical event occurrences. Here, additional grid reinforcements and technology investments that provide fast reserves can be decided if necessary. These three modules are now described in more details.

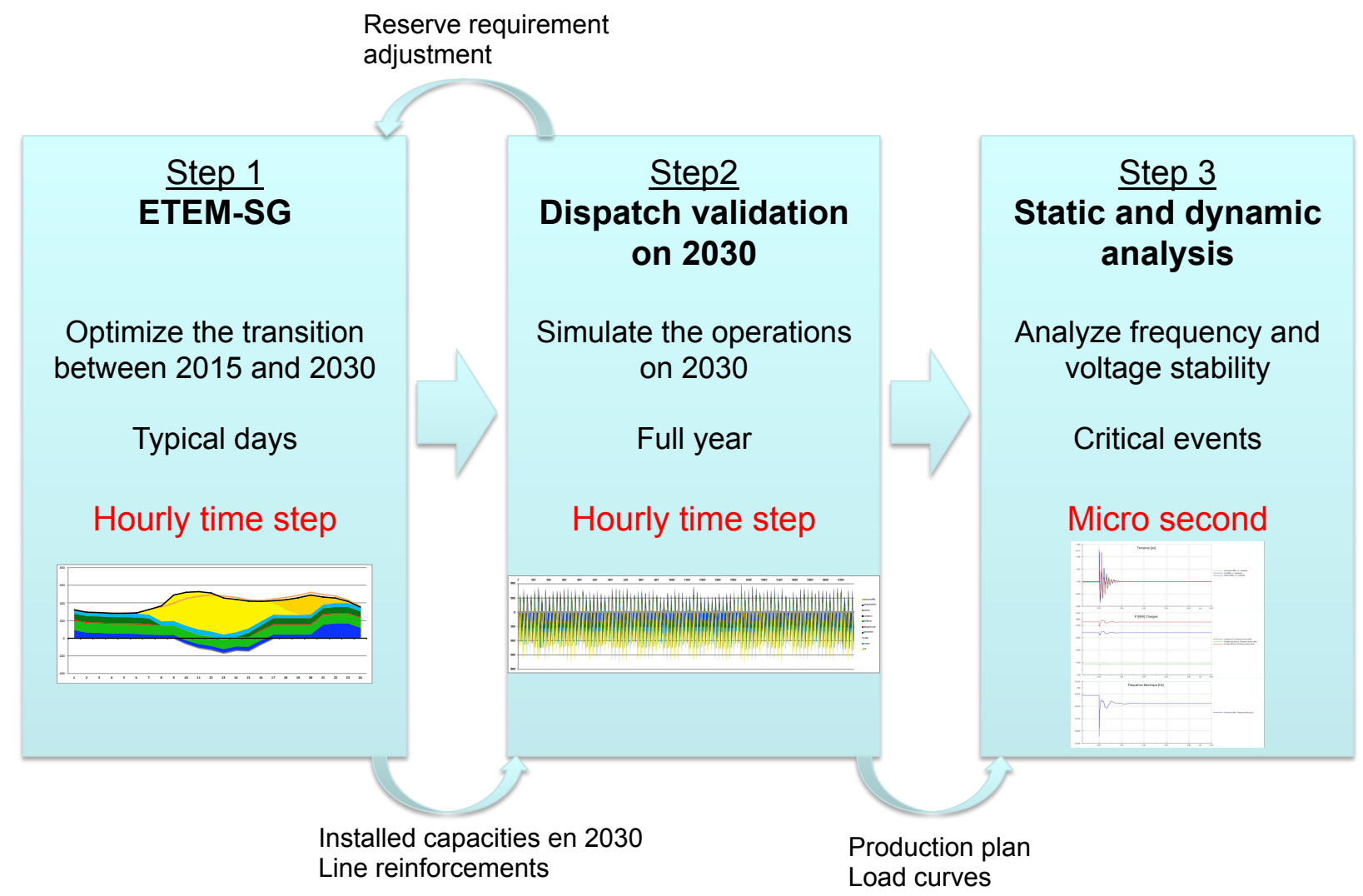

Figure 1: A global approach for designing transition to 100\% renewable electricity generation.

\subsection{Tier-1: Long-term capacity expansion and dispatch models}

ETEM-SG is a multi-sectoral, multi-energy, technology rich model (See Figure 2) specifically designed to analyze energy transition at regional level with a focus on the development of smart electricity system. A complete description of the ETEM-SG model is provided in 
[3]. A presentation of the possibility to represent demand response and distribution constraints and options in ETEM-SG is given in [2]. A presentation of the representation in ETEM-SG of power flow constraints and nodal marginal prices is given in [4]. ETEM-SG is a linear programming model, akin to the TIMES family of models $[5,10,14]$.

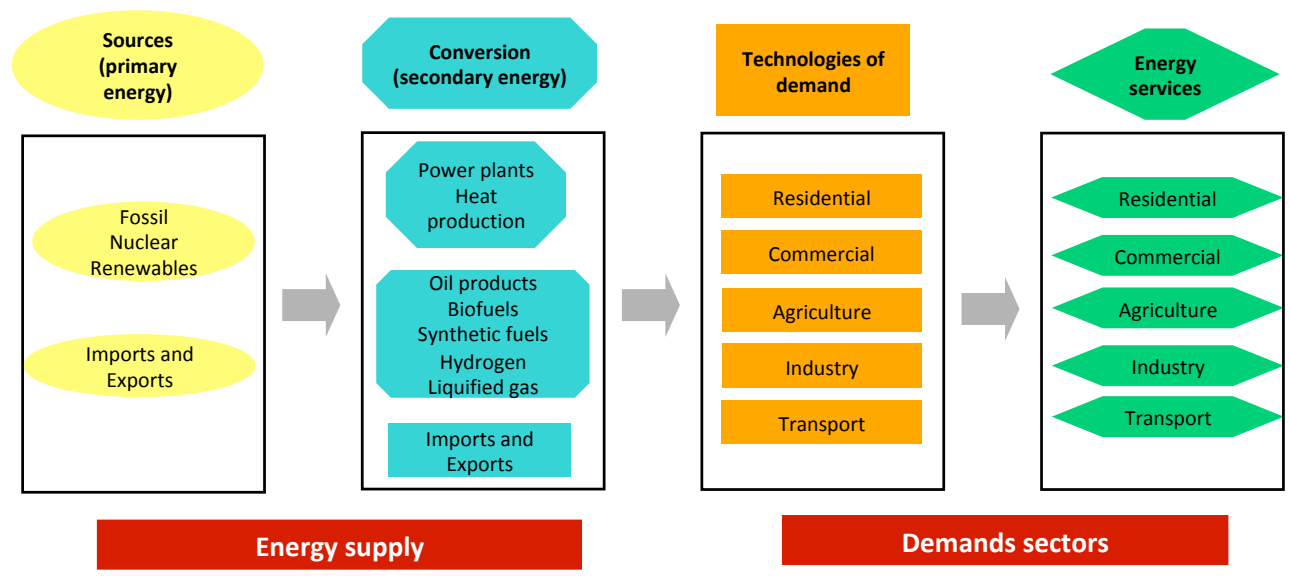

Figure 2: Reference Energy System

In its standard version the model is driven by exogenously defined useful energy demands (i.e. the demand for energy services) and imported energy prices. All technologies are defined as resource transformers and are characterized by technical coefficients describing input and output, efficiency, capacity bounds, date of availability (for new technologies), life duration, etc. Economic parameters define investment, operation and maintenance costs for each technology. The planning horizon is generally long enough to offer a possibility for the energy system to have a complete technology mix turnover.

Typically ETEM-SG simulates the development of an efficient regional energy system with a planning horizon of 20 to 50 years usually divided in periods $t \in T$ of 1 to 5 years (5 years in the simulations presented in this paper). In each period one considers a few typical days (e.g., 6 days corresponding to the three seasons - Winter, Summer, Spring-Fall - and two week day types - working weekday, weekend-Holiday -). Each of these days is subdivided into hours or groups of hours to obtain finally a set of timeslices $s \in S$ that will be used to represent load curves, distribution of demand and resource availability in different 
seasons and at different time of the day. This time structure is particularly important to represent correctly demand dynamics and the way one can exploit their flexibility (e.g., through demand-response mechanisms).

ETEM-SG computes an investment plan and a supply/demand balance at each timeslice for a set of typical days. In order to adapt to possible variations in demand (in particular, peak demand) and to compensate for the intermittency of variable renewable energies (e.g, wind turbines and solar energy), reserve requirements are then modeled in ETEM-SG as follows:

Reserve for peak demand. At each timeslice, ETEM-SG is informed of the average demand to be satisfied and the range of maximum variations observed in the past over this timeslice. ETEM-SG then guarantees additional production and/or storage capacities that can be mobilized to overcome these maximum demand variations.

Reserve for intermittency. At each timeslice, ETEM-SG determines the proportion of variable renewable production in the mix. Part of this variable production is then covered by an additional reserve that can be mobilized quickly in the event of a sudden loss of production. ETEM-SG requires this reserve to be greater than a given ratio of variable renewable output at each time-slice. In practice one chooses a ratio between $50 \%$ and $100 \%$. In Tier-2 a full year dispatch at an hourly time scale validates this reserve requirement, if it is feasible. In case of infeasibility the ratio must be augmented. In our case study, we are using a ratio of $70 \%$.

The fast reserve requirement for grid stability, such as kinetic energy linked to the inertia of the rotating masses, is assessed as part of the dynamic network study, described in Section 2.3 .

\subsection{Tier-2: Dispatch validation and reserve adjustment}

To validate and adjust the reserve requirements used to cope with intermittency of VRE's in the production plan proposed by ETEM-SG for a given year, one solves a full-year dispatch, with an hourly time-step (8760 hours), assuming representative annual demand and 
weather time series. These time series are built using the Typical Meteorological Year (TMY) methodology [16] which generates a representative annual profile of a most plausible/typical/normal year. It consists of selecting, for a given whole month, the measured hourly values of the month closest to the average month computed over the time period for which historical data were available (usually 10 years). These are not average values on a historical basis, but rather real time series of real values measured for a given month, the month closest to the average month over the period.

Starting from a low value around $50 \%$, the reserve ratio for intermittency used in ETEMSG is progressively increased when infeasibility of the dispatch problem is observed. Note that a perfect foresight optimization is done in this power dispatch model. If feasible the dispatch program obtained proves that there exists at least one demand/supply balance solution for a given year. Simulating a more realistic operating conditions and power dispatch decisions would require a stochastic programming/control approach, which was is out of scope for this study.

\subsection{Tier-3: Static and dynamic analysis}

The static and dynamic analysis aims at validating the optimized power system by considering physical constraints related to the operations of electrical systems. This analysis is conducted on some critical operating situations selected from the dispatch results and which correspond to situations that are particularly constraining for stability and static operating limits of the power grid. The power system analysis is carried out with PowerFactory [11], a reference tool for the simulation, analysis and modeling of power networks. It provides a library of typical models for different types of equipment and control systems (IEEE).

In the static analysis one observes the electrical system state at a given time in order to verify that the energy mix complies with standard grid rules. The tool computes the power flows (or load flow) and makes it possible to determine how the power produced is distributed on the network and what are the consequences of this distribution on the electrical quantities of the network. In particular, the following points are observed:

- Overloaded lines with respect to the maximum allowable current under steady state 
conditions (Imap).

- Voltage plan induced by the power flows and possible problems of network over- or under-voltage.

Based on these observations, reinforcement recommendations are proposed (e.g., reinforcement of transmission lines, additional reactive compensation equipments, dynamic operating rules of the generators, etc.). This static analysis is performed on three of the most demanding critical hours observed in the dispatch simulation.

The dynamic analysis concerns transient stability. It consists in checking the stability

of the electrical system following an extreme situation, e.g., a short-circuit default or the loss of a production group. The objective is to verify the stability of the electromechanical variables of the system, in the sense of asymptotic stability. Stability is observed with regard to voltage, frequency and alternators (angular stability). In order to guarantee the stability of the system, all these variables must remain in the admissible value ranges imposed by Operator.

\section{The case study of La Réunion}

In this section, the model used in the case study of the French island La Réunion is described. It has been used by ADEME to discuss with local authorities a possible transition of the power sector to $100 \%$ renewable production in 2030 .

\subsection{Time set}

The transition is represented on three 5-year periods from 2015 to 2030. To capture the different patterns of demands and of VRE production, we consider 8 typical days: a week day and weekend day for each of the four seasons. Each typical day is then decomposed in 24 hours. Each period thus contains 192 timeslices.

\subsection{Transmission network}

The model includes a description of the transmission grid displayed on Figure 3. Distribution networks have not been modeled. The costs associated with possible reinforcement of 
distribution networks are therefore not included in the economic results presented here. The costs associated with the transmission system are taken into consideration. The grid includes

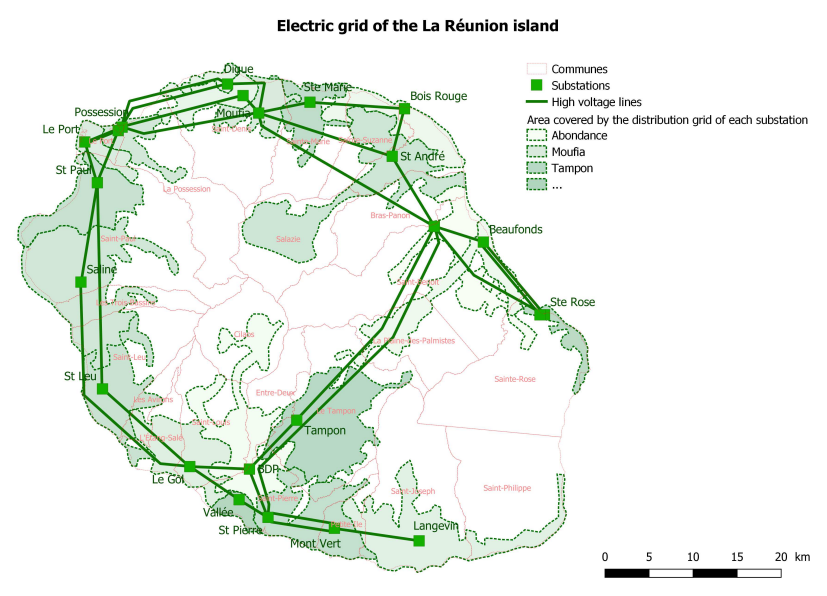

Figure 3: Transmission grid of La Réunion.

26 bus nodes and 43 transmission lines. Table 1 shows the transmission line characteristics, i.e., length, susceptance and maximum admissible flow capacity. 
Table 1: Transmission lines

\begin{tabular}{|c|c|c|c|}
\hline Line & Length $(\mathrm{km})$ & Susceptance (S) & Max capacity (MVA) \\
\hline Abondance - Beaufonds & 6 & 0.4 & 87.1 \\
\hline Abondance - Moufia & 25 & 0.1 & 42.5 \\
\hline Abondance - StAndre & 12 & 0.2 & 42.5 \\
\hline Abondance - StPierre & 45 & 0.1 & 70.5 \\
\hline Abondance - StRose & 18 & 0.1 & 87.1 \\
\hline Abondance - Takamaka & 8 & 0.3 & 42.5 \\
\hline BDP - Gol & 12 & 0.2 & 87.1 \\
\hline BDP - StPierre & 7 & 0.4 & 45.6 \\
\hline BDP - Tampon & 8 & 0.3 & 42.5 \\
\hline Beaufonds - BeaufondsZ & 4 & 0.6 & 37.8 \\
\hline Beaufonds - RDE & 12 & 0.2 & 87.1 \\
\hline BoisRouge - StAndre & 7 & 0.4 & 87.1 \\
\hline BoisRouge - StMarie & 17 & 0.2 & 87.1 \\
\hline Dattiers - Moufia & 3 & 1.0 & 45.6 \\
\hline Dattiers - Possession & 16 & 0.0 & 1.0 \\
\hline Digue - Moufia & 7 & 0.9 & 70.5 \\
\hline Digue - Possession & 21 & 0.3 & 45.6 \\
\hline Digue - Possession & 21 & 0.3 & 93.3 \\
\hline Gol - Vallee & 19 & 0.2 & 87.1 \\
\hline Gol - Saline & 29 & 0.0 & 1.0 \\
\hline Gol - StLeu & 15 & 0.2 & 45.6 \\
\hline Vallee - StPierre & 5 & 1.9 & 92.3 \\
\hline Langevin - MontVert & 16 & 0.0 & 1.0 \\
\hline Langevin - StPierre & 18 & 0.1 & 24.9 \\
\hline Marquet - Port & 7 & 0.9 & 96.4 \\
\hline Marquet - Port & 7 & 0.9 & 96.4 \\
\hline Marquet - Possession & 0 & 33.9 & 133.7 \\
\hline Marquet - Possession & 0 & 44.4 & 133.7 \\
\hline Marquet - StPaul & 10 & 0.3 & 45.6 \\
\hline MontVert - StPierre & 4 & 0.0 & 1.0 \\
\hline MontVert - StPierre & 4 & 0.0 & 1.0 \\
\hline Moufia - Possession & 18 & 0.2 & 73.1 \\
\hline Moufia - StAndre & 17 & 0.2 & 73.1 \\
\hline Moufia - StMarie & 11 & 0.3 & 87.1 \\
\hline Port - Possession & 7 & 0.8 & 70.5 \\
\hline Port - StPaul & 6 & 1.6 & 82.9 \\
\hline Port - StPaul & 6 & 1.6 & 82.9 \\
\hline RDE - StRose & 0 & 48.1 & 107.8 \\
\hline StPaul - Saline & 18 & 0.2 & 45.6 \\
\hline StPaul - StLeu & 28 & 0.0 & 1.0 \\
\hline Takamaka - Tampon & 27 & 0.1 & 42.5 \\
\hline Saline - StLeu & 16 & 0.2 & 45.6 \\
\hline Dattiers - Moufia & 3 & 1.2 & 70.5 \\
\hline
\end{tabular}




\subsection{Evolution of electricity demands}

The case study covers all electricity demands of the island - all sectors of activity and all uses - including electricity uses for transport. The scenario of electricity demand was carried out using the MedPro tool ${ }^{4}$, a prospective tool developed by Enerda, which produces projections of electricity demand and associated load curves. MedPro is a bottom-up technoeconomic model based on a detailed description of energy consumption and its determinants (e.g., economic growth, population, housing). This model was calibrated on the prospective scenario MDE+ from the official energy policy of La Réunion. The total electricity demand is decomposed in 12 usages as shown in Figure 4 for the MDE+ scenario. Then demands are distributed among buses and timeslices. The total demand reaches 3313GWh in 2030

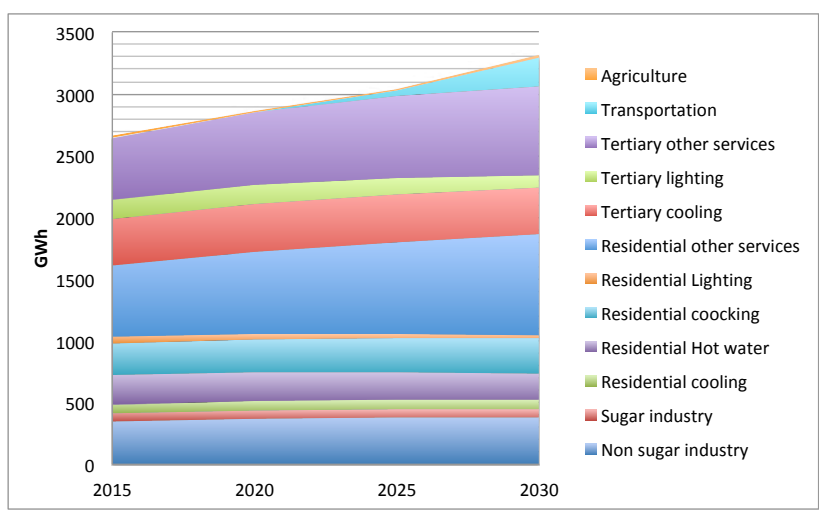

Figure 4: Sectorial demand for the MDE+ scenario.

(excluding network losses) whose 234GWh for electric mobility. We assume that $50 \%$ of the latter is shiftable through demand-response mechanisms.

\subsection{Techno-economic parameters}

In table 2, we report the list of technologies considered in ETEM-SG with cost assumptions and total potentials in 2030 .

\footnotetext{
${ }^{4}$ For information visit the Enerdata site https://www.enerdata.net/solutions/medpro-medee-model.html
} 
Table 2: Technologies with costs and potentials en 2030

\begin{tabular}{|c|c|c|c|c|}
\hline Technology & $\begin{array}{r}\text { Investment cost } \\
\mathrm{k} € / \mathrm{MW}\end{array}$ & $\begin{array}{r}\text { Fixed O\&M Cost } \\
k \in / M W\end{array}$ & $\begin{array}{r}\text { Variables O\&M } \\
\mathrm{k} \in / \mathrm{MW} / \mathrm{h}\end{array}$ & $\begin{array}{r}\text { Potential } \\
\mathrm{MW}\end{array}$ \\
\hline \multicolumn{5}{|c|}{ Solar } \\
\hline Residential roof (N/S) & 1540 & 16.8 & - & 610.5 \\
\hline Residential roof $(\mathrm{E} / \mathrm{W})$ & 1540 & 16.8 & - & 154.6 \\
\hline Tertiary roof $<2000 \mathrm{~m}^{2}(\mathrm{~N} / \mathrm{S})$ & 1240 & 16.8 & - & 126.5 \\
\hline Tertiary roof $<2000 m^{2}(\mathrm{E} / \mathrm{W})$ & 1240 & 16.8 & - & 43.5 \\
\hline Industrial roof $>2000 \mathrm{~m}^{2}(\mathrm{~N} / \mathrm{S})$ & 1240 & 16.8 & - & 105.6 \\
\hline Industrial roof $>2000 \mathrm{~m}^{2}(\mathrm{E} / \mathrm{W})$ & 1240 & 16.8 & - & 17.0 \\
\hline Ground & 800 & 12.6 & - & 94.2 \\
\hline Parking roof & 990 & 16.8 & - & 29.2 \\
\hline \multicolumn{5}{|c|}{ Hydroelectricity } \\
\hline Drinkable water adduction & 5150 & 206 & - & 1.2 \\
\hline Irrigation network & 1980 & 79 & - & 5.3 \\
\hline Sanitation network & 1980 & 79 & - & 0.1 \\
\hline Dam & 3720 & 112 & - & 128.2 \\
\hline Run-of-river dam & 2380 & 56.7 & - & 57.6 \\
\hline Marine pumped storage & 6420 & 192 & - & 50 \\
\hline Ocean Thermal Energy & 16200 & - & 0.25 & 7 \\
\hline \multicolumn{5}{|c|}{ Wind } \\
\hline Onshore & 2380 & 60 & - & 142.5 \\
\hline Offshore & 5060 & - & 0.15 & 50 \\
\hline \multicolumn{5}{|c|}{ Biomass } \\
\hline Thermal power plant (bagasse/coal/biomass) & 4500 & 163 & 0.07 & 381.9 \\
\hline Thermal power plant (sugar cane) & 2160 & 93 & 0.13 & 14.5 \\
\hline Thermal power plant (green waste) & 2160 & 93 & 0.13 & 4.3 \\
\hline Thermal power plant (bio waste) & 2160 & 93 & 0.13 & 1.3 \\
\hline Incineration plant & 7700 & 290 & - & 53.7 \\
\hline Small biomass plant & 2160 & 93 & 0.35 & 5.1 \\
\hline Bioethanol & 1470 & 87 & 0.071 & 41.0 \\
\hline Biogas & 5240 & 90.6 & 0.17 & 29.9 \\
\hline \multicolumn{5}{|c|}{ Geothermy } \\
\hline Deep & 5350 & 123 & 0.012 & 15 \\
\hline
\end{tabular}

Using these cost parameters ETEM-SG computes the overall system cost of energy production, which depends on the characteristics and resources specific to each production site. For example, an illustration of the average costs by energy sector is given in Figure 5 . When different technologies exist for the same sector, the envelope cost is presented on the graph (minimum and maximum costs). In 2015, the model reconstructs a complete production cost consistent with that published by the French Energy Regulatory Commission (CRE). The cost projection assumptions of the different technologies selected are all conservative compared to the different studies from literature. 


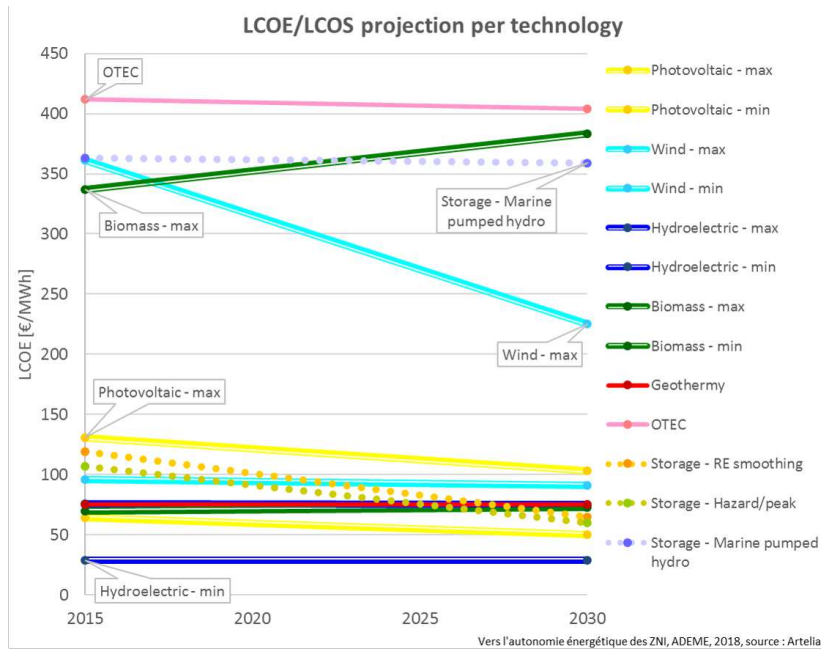

Figure 5: Average leverized production costs for RES and storage technologies.

Other parameters of ETEM-SG concern e.g. availability factors, efficiencies and date of availability. Figure 6 gives the nodal residual capacities of reference energy system (RES) in 2015 and the identified RES potentials in 2030, by energy form.
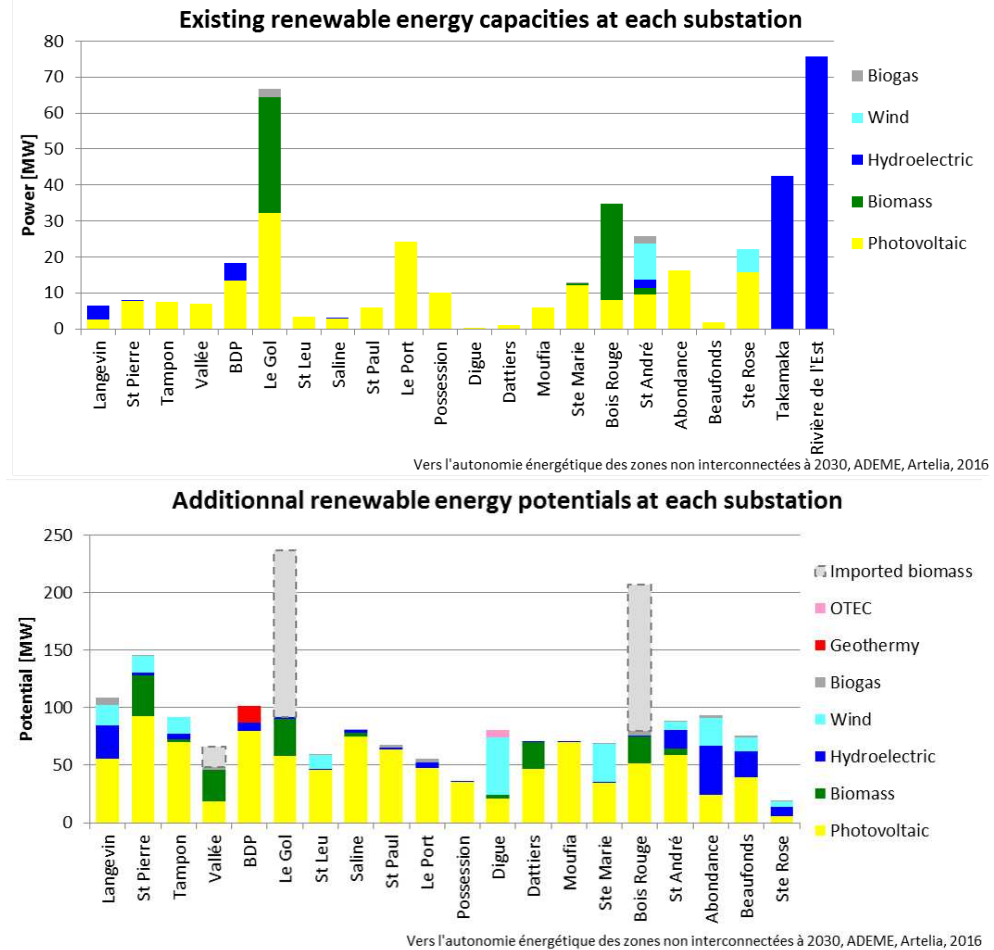

Figure 6: Nodal residual capacities in 2015 and renewable potentials in 2030. 


\section{Simulation results}

This section presents in more details the simulation results for a transition to $100 \%$ renewable of the La Réunion electricity sector. We first detail the optimal system proposed

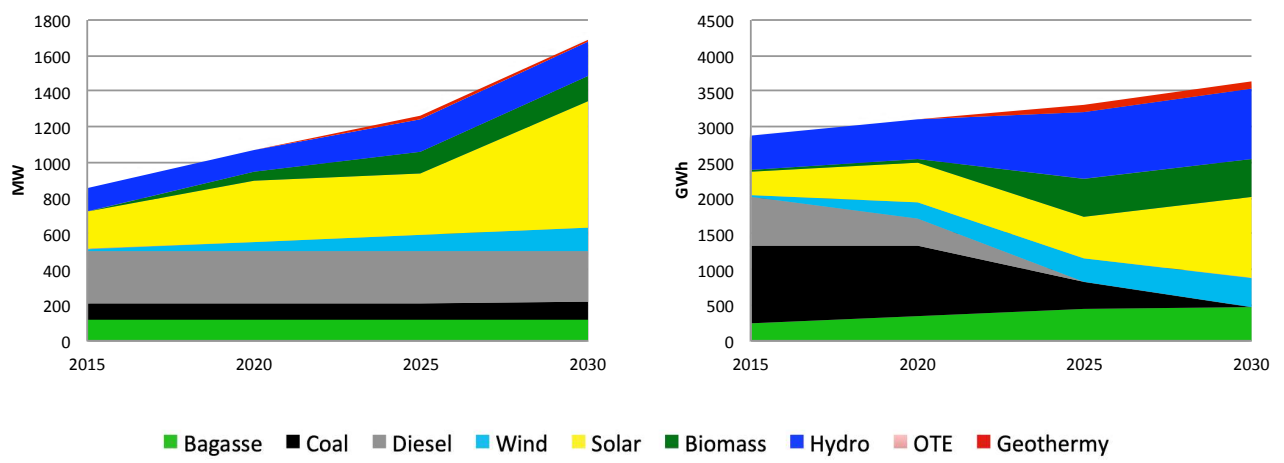

Figure 7: Evolution of the installed capacities (left) and energy mix (right) on the 2015-2030 period.

by using the three-tiered modeling approach. Then we summarize the findings of the static and dynamic analyses. Finally, we report the cost analysis of the transition to a $100 \%$ renewable power system in 2030.

\subsection{Optimal system evolution}

Figure 7, shows the evolution of installed capacities and of the energy mix by energy form on the 2015-2030 period. We observe that the $100 \%$ renewable objective is achieved in 2030 with significant investments in distributed photovoltaic panels, with a total capacity of 713MW which represents $60 \%$ of its identified potential. Hydro (193MW), biomass (140MW), bagasse (120 MW) and geothermal (15MW) sources are exploited at their maximum potentials providing the system with a stable production. Similarly to solar intermittent production, onshore wind mills are not fully exploited reaching in 2030 a capacity of 125MW (90\% of the potential). Offshore wind and Ocean Thermal Energy technologies are not economically competitive enough to be deployed. Note that fossil-fuel-based power plants in the system capacity are not used anymore in 2025 for diesel and 2030 for coal. Globally, variable energy sources (PV, wind and hydro) generate $69 \%$ of the energy mix in 2030, much more that the 30\% regulatory limit in France. Finally, this energy mix leads to 
two grid reinforcements limited to $18 \mathrm{MW}$, i.e, $7.2 \mathrm{MW}$ on the Abondance-Moufia line and 10.8MW on the Abondance-Saint André line.

Figure 8 shows the nodal location of the production units by energy form. It also displays storage capacities that provide the system with the needed reserve to deal with production intermittency and demand fluctuations. As expected, the low network reinforcements mentioned above is explained by distributed production throughout the island and in particular close to demand centers. A total capacity of 596MW of lithium batteries is invested to ensure the hourly demand supply balance in ETEM-SG on typical days. These reserve capacities make a complete 2030 dispatch simulation feasible. Among those 596MW of batteries, $340 \mathrm{MW}$ are specifically dedicated to demand variability and $265 \mathrm{MW}$ to intermittent energies.

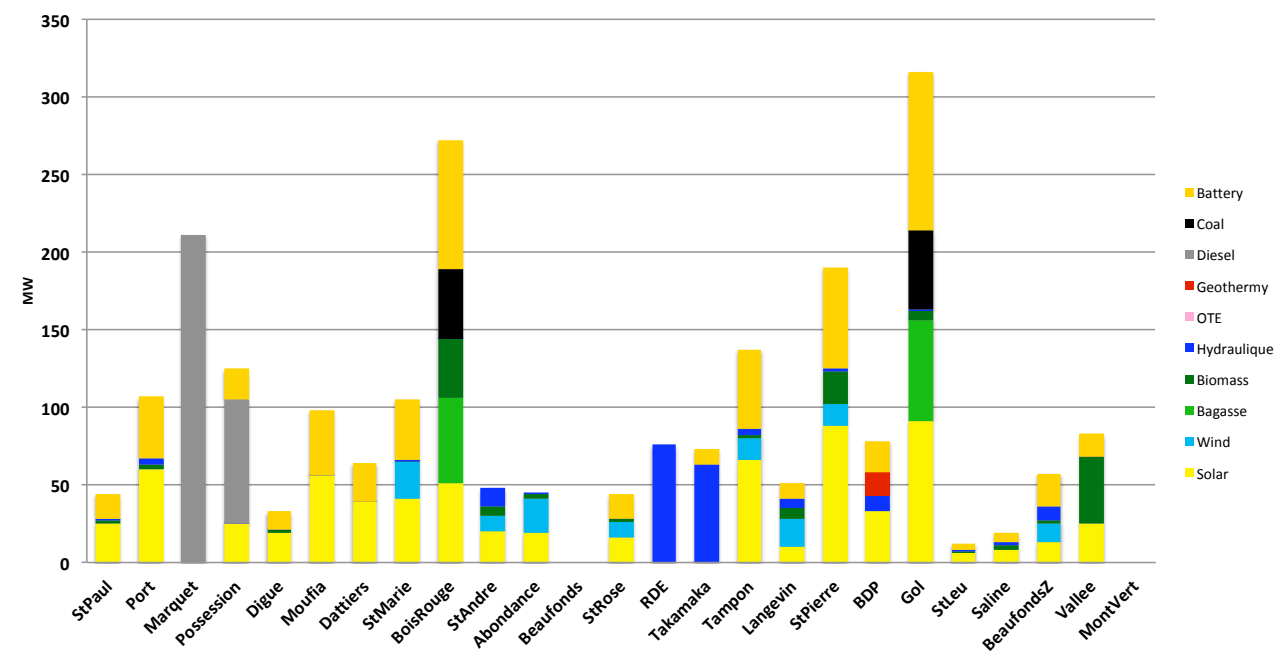

Figure 8: Installed capacities at each bus in 2030.

Figures 9 and 10 give the load curves computed by ETEM-SG for each typical day (week and weekend, respectively), and for each season. The orange and black lines represent the demand patterns before and after piloting the EVs charging, respectively. Storage occurs when production exceeds demand (the areas below the x-axis) at sunshine peak hours while discharging, shown in dark yellow color, appears mostly in the evening between $16 \mathrm{~h}$ and $22 \mathrm{~h}$. One notices that bagasse production only appears during the sugar industry periods and is 
replaced mainly by hydro production for the rest of the year.
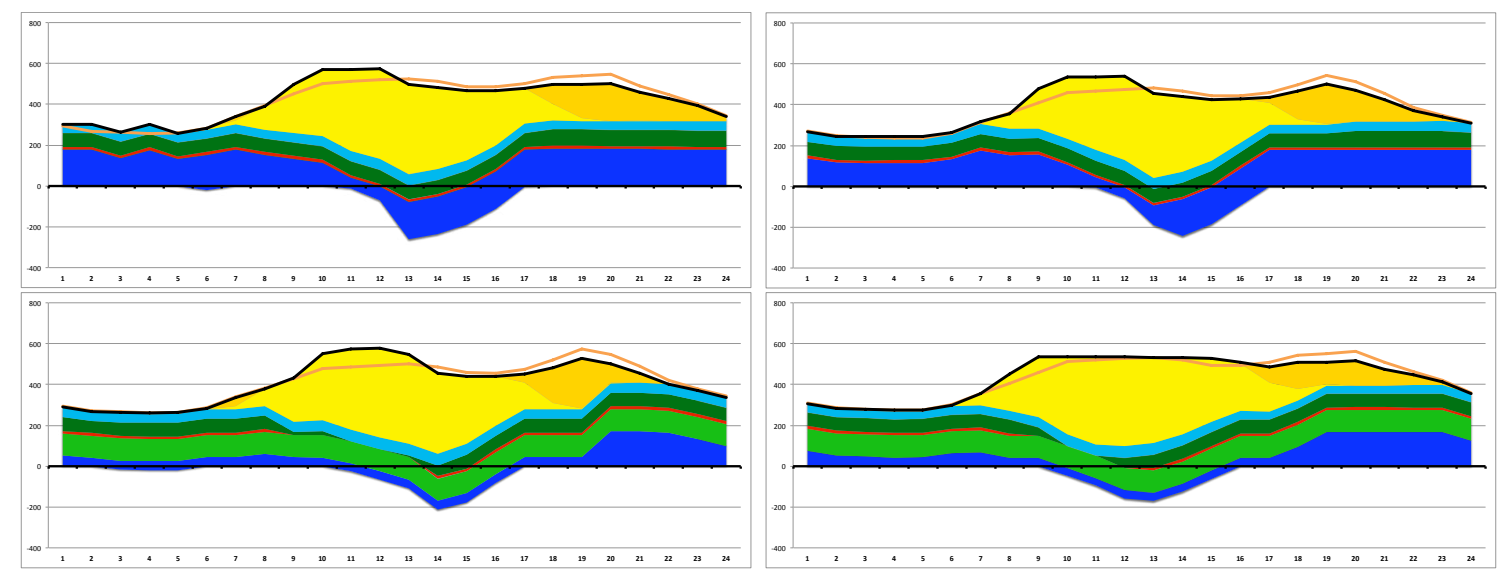

Bagasse Coal Diesel Wind Solar $\square$ Biomass $\square$ Hydro $\quad$ OTE $\square$ Geothermy

Figure 9: Hourly load flow for the four week typical days (winter, springer, summer and autumn) in MW.
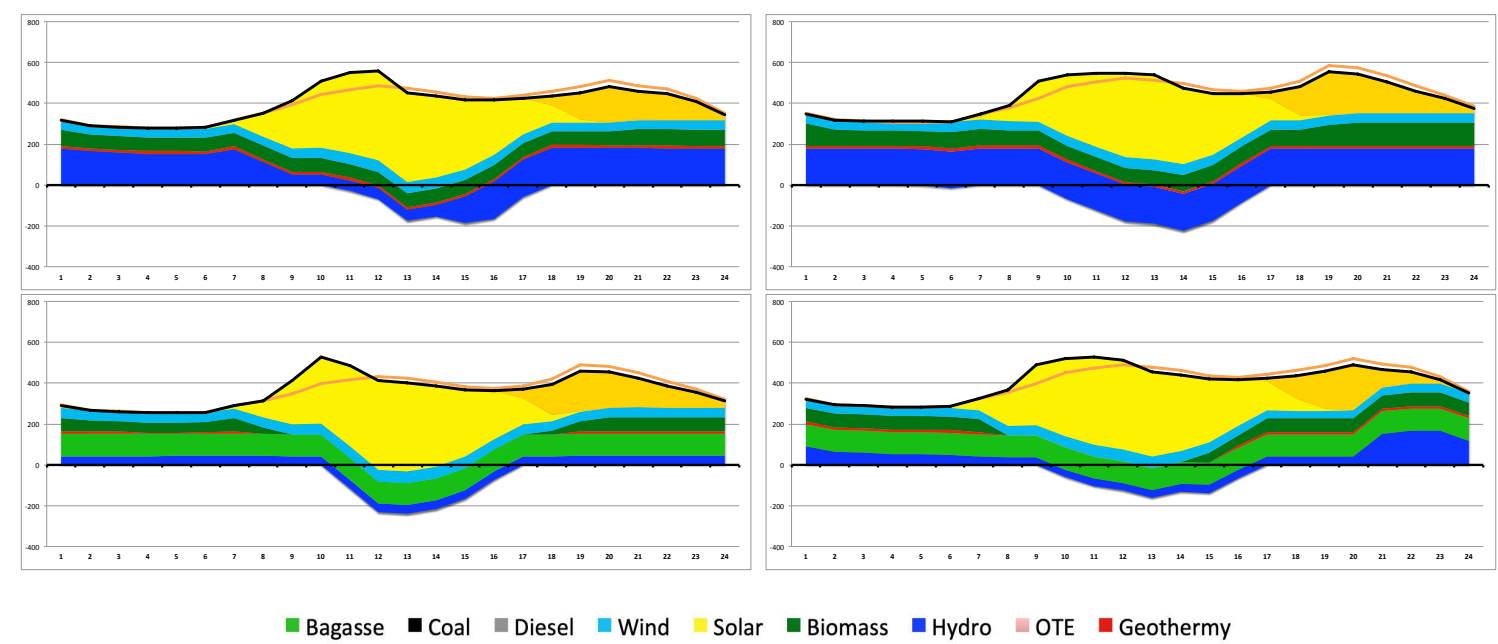

Figure 10: Hourly load flow for the four weekend typical days (winter, springer, summer and autumn) in MW.

\subsection{Dispatch simulation in 2030}

Figure 11 illustrates the dispatch simulation output. It shows a possible hourly contribution of each production sector over a full 2030 year ensuring the hourly supply-demand balance. The resulting energy system from ETEM-SG and dispatch simulation displayed 
in Figure 11 have been obtained by increasing iteratively the reserve requirement until dispatch feasibility. The process has yielded a reserve requirement corresponding to $70 \%$ of the variable energy production at any time step. According to ETEM-SG, this time dependent reserve is ensured either by batteries, hydro dams or biomass thermal plants.

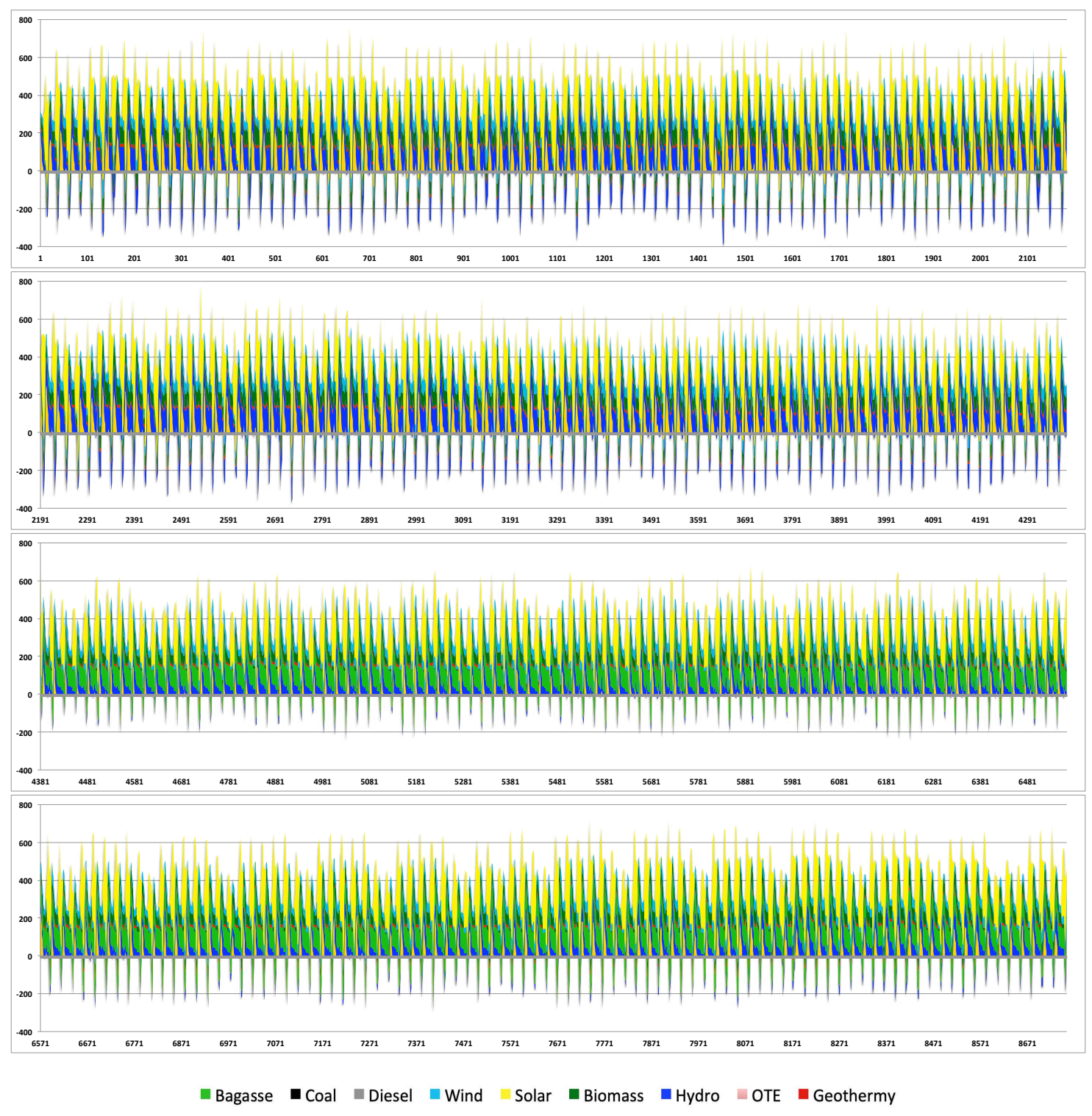

Figure 11: Hourly load flow from the dispatch model in MW. 


\subsection{Implications on system stability in 2030}

Given the high shares of variable resources in the production mix (69\%), a static and dynamic validation is required to study the behavior of the electricity system in case of disruptive incidents. In this paper, we focus our analysis on three extreme operating situations observed in the dispatch simulations shown on Figure 11. In Figure 12, we display the 8760 operating points according to their level of production and VRE rate. We selected the three following most critical situations for network stability: 1) the lowest decentralized production rate, 2) the highest annual peak load and 3) the maximum penetration of wind and photovoltaic productions.

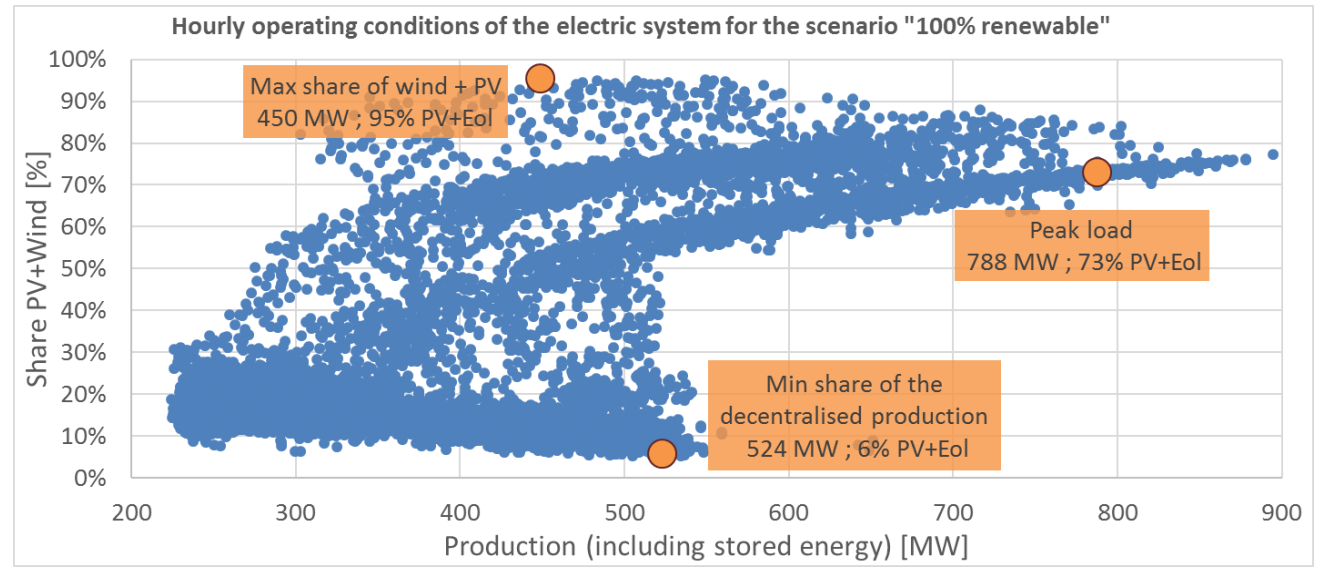

Figure 12: Hourly operating management points from dispatch simulation in 2030.

Conclusions on the static analysis. Static studies under PowerFactory have made it possible to determine at each operating point the state of the voltage plan. This constraint is not considered by the ETEM-SG model but is of great importance in the design and operation of electricity grids. The voltage plan may also require reinforcement of the network if it does not respect the limits defined by the operator which is not the case here.

Usually, the voltage is controlled by alternators by injection or reactive power absorption on the network. In the scenarios of high decentralized production, the maintenance of the voltage can not be assured by the conventional power plants, these being generally disconnected at these times. In addition, the diffuse PV and the wind turbines are connected to the 
distribution network and therefore do not directly regulate the voltage on the transmission network.

The maintenance of the voltage is therefore essentially provided by the battery farms, centralized and connected to the source stations by dedicated High Voltage departures, which allow the supply and/or absorption of reagent at any time of the day. It has not been necessary to resort to the addition of local reactive compensation (capacitors), although this may be an alternative if the batteries are not enough.

It should be noted that these results depend greatly on the hypotheses taken concerning the battery farms (centralized connection, cos phi of 0.9 , installed powers relatively important, etc.). Under these assumptions, the voltage plane is maintained within the acceptable range.

Conclusions on the dynamic analysis. The dynamic stability studies were carried out from the operating point 3 above (i.e., the lowest decentralized production rate). It corresponds to a very restrictive situation of low inertia of the electrical system, low power short circuit and high variability of production.

The results of the following 3 case studies are presented below:

- Case study 1: Voltage drop (short-circuit) of $250 \mathrm{~ms}$ on the busiest line (Gol-Saline) then elimination of the fault by opening of the circuit-breakers;

- Case study 2: Sudden loss of a 53MW plant at full load;

- Case Study 3: Sudden loss of the entire PV injection at the Le Gol bus node.

For these three events, despite the very low inertia of the power grid, resulting in a rapid variation in its frequency, the dynamic stability of the system is ensured given the very fast response time of the batteries. Such an electrical system can therefore remain stable in the face of significant incidents. Nevertheless, because of the simplifying assumptions made for network modeling, this result, while encouraging, does not support the conclusion that the actual system is stable and secure in all operating conditions. 
As an illustration, Figure 13 shows some network frequency and voltage curves for the case study 1 . One observes a quick return to stability, in less than two seconds after the
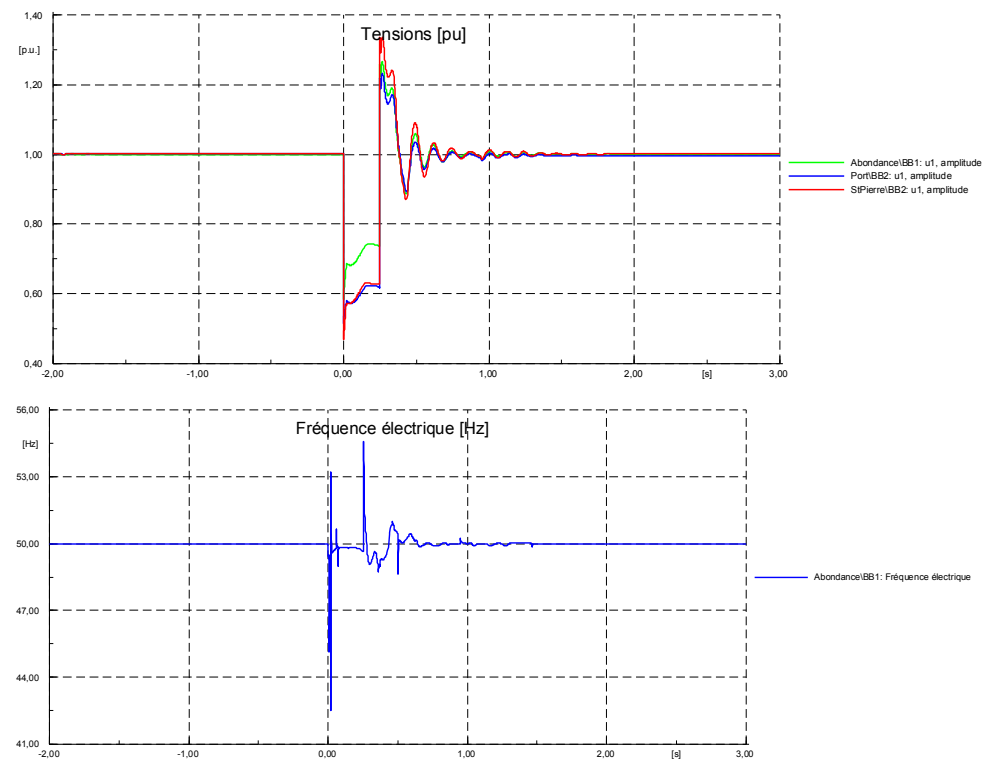

Figure 13: Frequency (Frequence electrique $(\mathrm{Hz})$ ) and voltage (Tensions (pu)) curves in case of a voltage drop.

elimination of the defect. This is faster than what is observed today (usually several seconds or tens of seconds) and is mainly allowed by the high reactivity of power electronics-based interfaces.

During the fault period $(250 \mathrm{~ms})$, the voltage across the entire network drops. The dynamic support of the voltage is essentially ensured by the centralized PV on the ground and the storage batteries, connected to the high voltage grid or on dedicated medium voltage outputs, whose reactive power injection makes it possible to maintain the voltage.

However, the short circuit power at the fault level is very low compared to the standard values. This confirms that very high penetration rates of productions interfaced by inverters can cause problems related to the detection of defects and therefore their proper disposal. In addition to imposing strict operating constraints on diffuse installations, in such a context, it would probably be necessary to modify or even completely rethink the network protection plans. 
As an illustration, Figure 14 shows some curves of frequencies and voltages of the network for the case study 2, i.e., sudden loss of a power plant at full load. The results for the case study 3 are similar. The different quantities observed return very quickly to stability in less

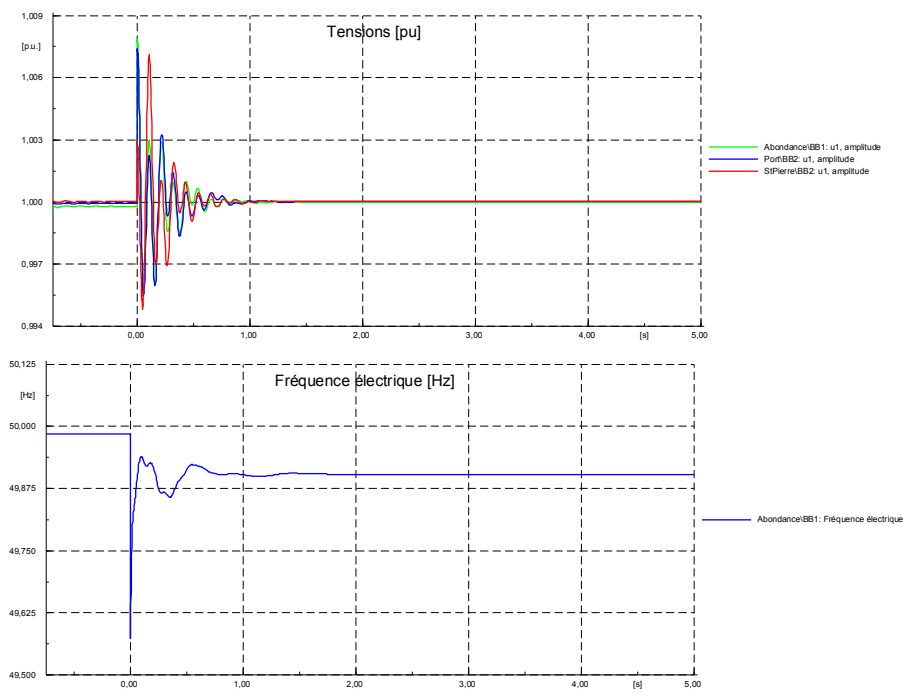

Figure 14: Frequency (Frequence electrique $(\mathrm{Hz})$ ) and voltage (Tensions (pu)) curves in case of a sudden loss of a 53MW plant at full load.

than two seconds after the triggering of the group. Given the low proportion of connected rotating machines, the rotating reserve is almost zero in this scenario and the bulk of the mobilized power reserve comes from the batteries.

Batteries respond quickly to the observed frequency deviation. It is important to note that the fall of the frequency response is very fast after the triggering of the group, due to the very low inertia of the electrical system. The performance of frequency regulation by the batteries is therefore fundamental for maintaining the stability of the system.

The large installed power capacity of batteries, under the assumptions of parameters considered, allow the system to keep a small static difference after stabilization of the frequency (of the order of $100 \mathrm{mHz}$ ). The frequency therefore remains in the range [48-52 Hz] which corresponds to the normal operating range of the system in all the cases studied. The load shedding thresholds are therefore not exceeded in the cases studied, thus minimizing undistributed energy. 


\subsection{Cost analysis}

The economic indicators obtained are summarized in Table 3. As shown on Figure 15, the

Table 3: Economic results

\begin{tabular}{lr}
\hline \multicolumn{2}{c}{ On the 2015-2030 period } \\
\hline Total discounted cost & $5659 \mathrm{M} €$ \\
Investment cost & $2579 \mathrm{M} €$ \\
Reinforcement cost & $1.5 \mathrm{M} €$ \\
\hline \multicolumn{1}{c}{ On the equipment lifetime } \\
\hline Average LCOE & $126 € / \mathrm{MWh}$ \\
Average LCOE for new units & $100 € / \mathrm{MWh}$ \\
Median LCOE & $88 € / \mathrm{MWh}$ \\
\hline \multicolumn{1}{c}{ Marginal costs in 2030} \\
\hline Average marginal cost & $176 € / \mathrm{MWh}$ \\
Maximum marginal cost & $1378 € / \mathrm{MWh}$ \\
Minimum marginal cost & $0 € / \mathrm{MWh}$ \\
\hline
\end{tabular}

most important items of discounted costs for the 2015-2030 period are the three fossil-fueled plants (oil TACs, coal-fired power plants, diesel plants) and cogeneration biomass plant.

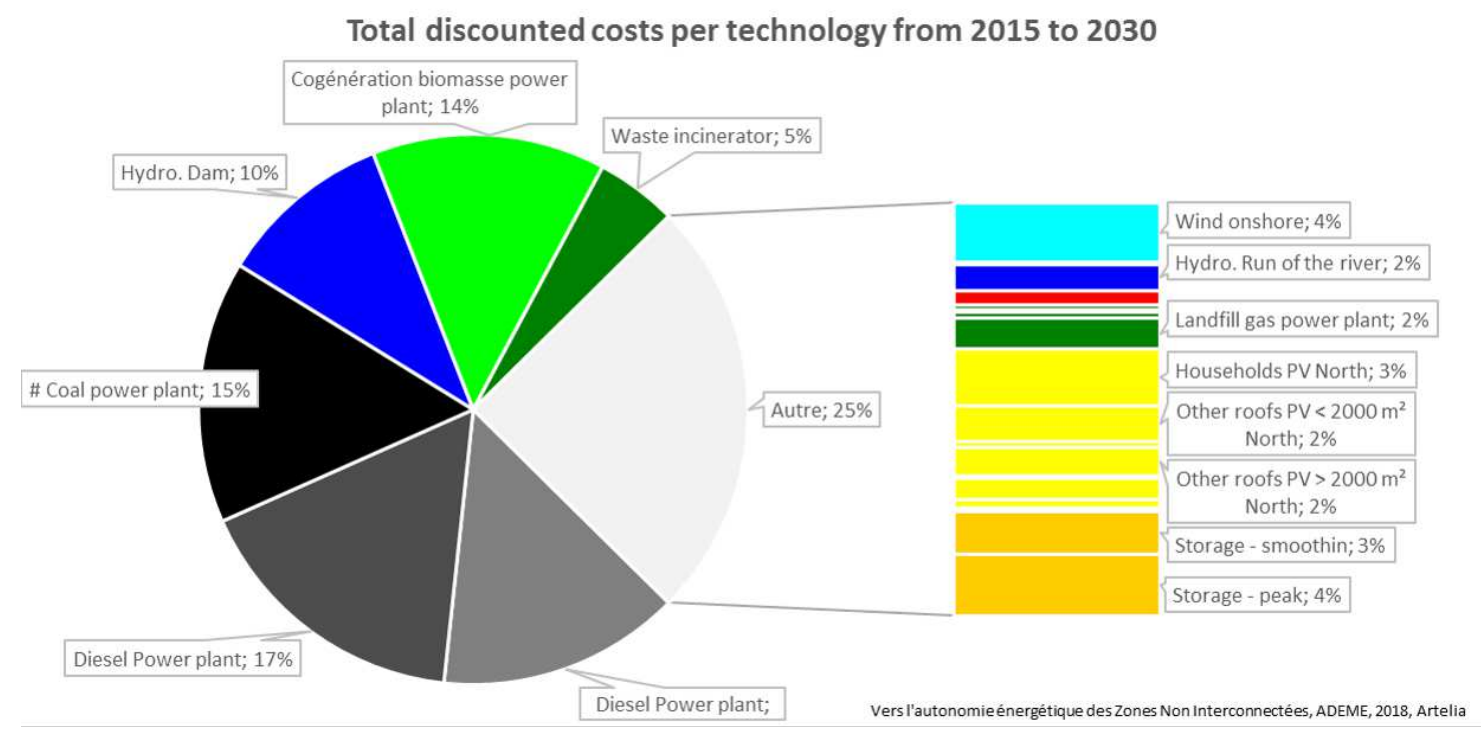

Figure 15: Repartition of total discounted costs on the 2015-2030 period. 


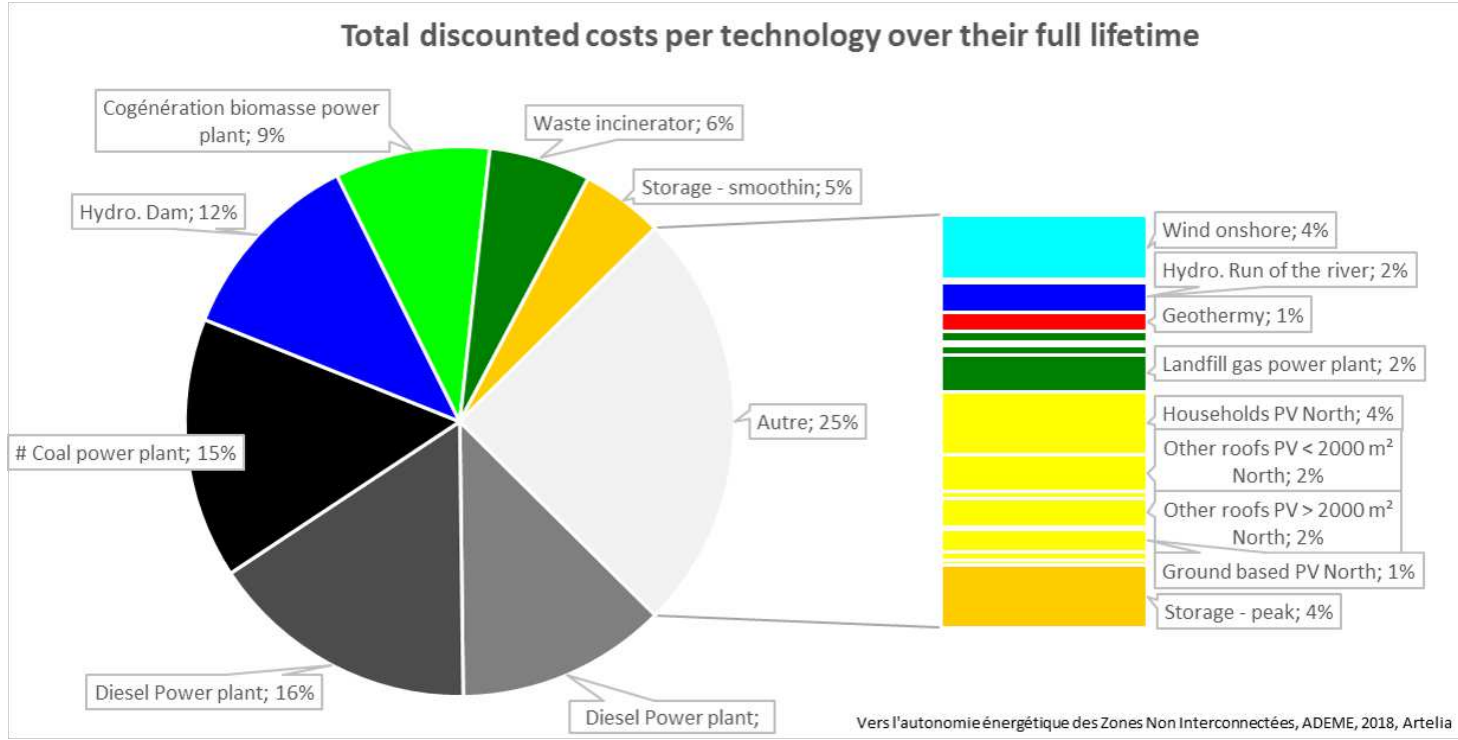

Figure 16: Repartition of total discounted costs on the equipment life duration.

In this scenario, fossil plants are completely replaced by renewable energies by 2030 . Two energy storage technologies together account for the largest part of the energy cost in 2030. Note that the weight of storage for regulating the renewable energy production is equivalent to that to cover hazards and peak with respectively $12 \%$ and $11 \%$ of costs. After storage, the sector weighing the most on the full cost of production remains a sector using a fuel (biomass cogeneration) with $14 \%$ of the costs, followed by the hydropower dam and the incinerator.

\section{Conclusion}

This paper proposes a three-tiered global approach for designing energy transition towards $100 \%$ renewable electricity production in non-interconnected areas. The capacity expansion model ETEM-SG is first used to determine an optimal investment plan, based on typical days, on the whole transition period 2015-2030. Then a dispatch model simulates and validates the demand/supply equilibrium on a full year and proposes reserve adjustment if needed. Finally, static and dynamic studies are performed on the most critical situations of the dispatch simulations for extreme events impacting voltage and frequency network stability. The approach has been validated and used for several isolated French territories, 
islands or remote areas.

The implementation to La Réunion case study leads to the following conclusions. First we find that local renewable potentials are sufficient to ensure a 100\% renewable and local electricity mix while satisfying at all times supply demand balance at an hourly basis for a full year with representative weather time series. This necessitates a significant investment in storage capacity. Second, existing diesel plants would no longer be competitive with renewable energies by 2025, even when taking into consideration the system services they provide. More precisely, diesel units variable costs would already be higher than the total costs of the competitive renewable energy technologies. Decommissioning of conventional power plants will have a significant effect on the inertia of the electrical system. This point was addressed in our analysis.

Finally, the results of the static and dynamic simulations show no divergence of the main electromechanical quantities of the network (Frequency, Voltage, Current, etc ...) for the tested cases. The electrical system can therefore remain stable in the face of such significant incidents, under the somewhat simplifying assumptions retained. It is therefore important to recall the importance of the modeling assumptions in the static and dynamic analysis. Any modification of these assumptions, in particular concerning the installed capacities and the parameters of the equipments represented in the power system model, could affect the conclusions. In particular, the simulations carried out in the present study concern only the high voltage network since in the power system model, one considered that decentralized production units, like e.g plug-in hybrid electrical vehicles (PHEV), will not participate in power the supply, nor in the reactive power compensation. As a consequence, they do not participate in the voltage adjustment for the $63 \mathrm{kV}$ network. In practice, these devices could participate in the voltage control on the distribution networks, but it would have little influence on the high voltage network.

\section{Author Declarations}

Funding. The Research has been funded by ADEME, France. First and forth authors gratefully acknowledge the support provided by Qatar National Research Fund under Grant 
Agreement No. NPRP10-0212-170447. The first author also acknowledges support provided by FONDECYT 1190325 and by ANILLO ACT192094, Chile.

Conflicts of interest/Competing interests. Not applicable.

Availability of data and material/ Data availability. The datasets generated during and/or analysed during the current study are available from the corresponding author on reasonable request.

Code availability. The ETEM-SG model used in this research is an open-source model.

Authors' contributions. All authors contributed to the research and the manuscript. All authors read and approved the final manuscript.

\section{References}

[1] ADEME. Vers l'autonomie energetique en zone non interconnectee a l'horizon 2030, rapport final d'étude pour l'île de la réunion. Technical report, 2019.

[2] F. Babonneau, M. Caramanis, and A. Haurie. A linear programming model for power distribution with demand response and variable renewable energy. Applied Energy, 181(1):83-95, November 2016.

[3] F. Babonneau, M. Caramanis, and A. Haurie. ETEM-SG: Optimizing regional smart energy system with power distribution constraints and options. Environmental Modelling and Assessment, 22(5):411-430, 2017.

[4] F. Babonneau and A. Haurie. Energy technology environment model with smart grid and robust nodal electricity prices. Annals of Operations Research, 274:101-117, 2019.

[5] C. Berger, R. Dubois, A. Haurie, E. Lessard, R. Loulou, and J.-P. Waaub. Canadian MARKAL: An advanced linear programming system for energy and environmental modelling. INFOR, 30(3):222-239, 1992.

[6] Thomas Brown, Jonas Hörsch, and David Schlachtberger. PyPSA: Python for Power System Analysis. Journal of Open Research Software, 6(1):4, January 2018. 
[7] Agence de l'Environnement et de la Maîtrise de l'Énergie. L'exercice de prospective de l'ADEME, Vision 2030-2050. Technical report, ADEME, 2012.

[8] M. Drouineau, E. Assoumou, V. Mazauric, and N. Maïzi. Increasing shares of intermittent sources in reunion island: Impacts on the future reliability of power supply. Renewable and Sustainable Energy Reviews, 46:120-128, 2015.

[9] M. Drouineau, N. Maïzi, and V. Mazauric. Impacts of intermittent sources on the quality of power supply: The key role of reliability indicators. Applied Energy, 116:333-343, 2014.

[10] E. Fragnière and A. Haurie. A stochastic programming model for energy/environment choices under uncertainty. Int. J. Environment and Pollution, 6(4-6):587-603, 1996.

[11] Francisco M. Gonzalez-Longatt and José Luis Rueda (eds.). PowerFactory applications for Power system analysis. Springer, 2020.

[12] S. Hilpert, C. Kaldemeyer, U. Krien, S. Günther, C. Wingenbach, and G. Plessmann. The Open Energy Modelling Framework (oemof) - A new approach to facilitate open science in energy system modelling. Energy Strategy Reviews, 22:16-25, November 2018.

[13] D. H. Loughlin. Using MARKAL Model to Evaluate Factors Influencing Low Carbon Power Generation. In International Congress on Sustainability Science Engineering ICOSSE, Cincinnati, Ohio (USA), 2009.

[14] R. Loulou and M. Labriet. ETSAP-TIAM: the times integrated assessment model part i: Model structure. Computational Management Science, 5(1):7-40, 2008.

[15] S. Moret, F. Babonneau, M. Bierlaire, and F. Maréchal. Decision support for strategic energy planning: a robust optimization framework. European Journal of Operational Research, 2019.

[16] S. Wilcox and W. Marion. Users manual for tmy3 data sets. Technical report, National Renewable Energy Laboratory, 2018. 